\title{
(อ) OPEN ACCESS \\ Cigarette smoke exposure and alveolar macrophages: mechanisms for lung disease
}

\author{
Sebastian T Lugg, Aaron Scott 두, Dhruv Parekh, Babu Naidu, David R Thickett
}

Birmingham Acute Care Research Group, Institute of Inflammation and Ageing, University of Birmingham, Birmingham, UK

\section{Correspondence to}

Dr David R Thickett, Birmingham Acute Care Research Group, Institute of Inflammation and Ageing, University of Birmingham, Birmingham, UK; d.thickett@bham.ac.uk

Received 1 October 2020 Revised 19 March 2021 Accepted 22 March 2021
D) Check for updates

(c) Author(s) (or their employer(s)) 2021. Re-use permitted under CC BY-NC. No commercial re-use. See rights and permissions. Published by BMJ.

To cite: Lugg ST, Scott $A$, Parekh D, et al. Thorax Epub ahead of print: [please include Day Month Year]. doi:10.1136/

thoraxinl-2020-216296

\section{ABSTRACT}

Cigarette smoking is the leading cause of preventable death worldwide. It causes chronic lung disease and predisposes individuals to acute lung injury and pulmonary infection. Alveolar macrophages are sentinel cells strategically positioned in the interface between the airway lumen and the alveolar spaces. These are the most abundant immune cells and are the first line of defence against inhaled particulates and pathogens. Recently, there has been a better understanding about the ontogeny, phenotype and function of alveolar macrophages and their role, not only in phagocytosis, but also in initiating and resolving immune response. Many of the functions of the alveolar macrophage have been shown to be dysregulated following exposure to cigarette smoke. While the mechanisms for these changes remain poorly understood, they are important in the understanding of cigarette smoking-induced lung disease. We review the mechanisms by which smoking influences alveolar macrophage: (1) recruitment, (2) phenotype, (3) immune function (bacterial killing, phagocytosis, proteinase/anti-proteinase release and reactive oxygen species production) and (4) homeostasis (surfactant/lipid processing, iron homeostasis and efferocytosis). Further understanding of the mechanisms of cigarette smoking on alveolar macrophages and other lung monocyte/macrophage populations may allow novel ways of restoring cellular function in those patients who have stopped smoking in order to reduce the risk of subsequent infection or further lung injury.

\section{INTRODUCTION}

Cigarette smoking remains the single most preventable cause of death and disease worldwide and is the leading cause of chronic obstructive pulmonary disease (COPD). The disease processes in COPD are multifaceted involving oxidative stress, inflammation, proteinase/anti-proteinase imbalance, tissue destruction and inadequate repair. Alveolar macrophages (AMs) play an important role in these processes. AMs are also implicated in the cigarette smoke (CS)-related disease development of lung cancer and interstitial lung disease as well as in the increased susceptibility to pulmonary infections and acute lung injury. However, the mechanisms of CS exposure and AMs in lung disease remain poorly understood. The current understanding is reviewed (summarised in figure 1).

\section{CIGARETTE SMOKE}

CS is an aerosol consisting of solid and liquid droplets (the particulate ('tar') phase) in a gaseous phase and contains over 4500 different substances, ${ }^{1}$ which have various toxic, mutagenic and carcinogenic

Figure 1 Mechanisms for disease in cigarette smoke exposure of alveolar macrophages. IL, interleukin; MMP, matrix metalloproteinase; ROS, reactive oxygen species. 
effects. These include nicotine, tar, ammonia, carbon monoxide, carbon dioxide, formaldehyde, acrolein, acetone, polyaromatic aromatic hydrocarbons (PAHs), hydroxyquinone, nitrogen oxides and cadmium. ${ }^{2}$ Inhaled particulate matter from CS is deposited in the respiratory tract depending on the size, with larger particulates in the upper airways and smaller particulates deposited in the alveoli. CS causes oxidative stress resulting in a chronic low-grade inflammation and recruitment of inflammatory cells to the airways by activation of epithelial cells, AMs, neutrophils and T lymphocytes. ${ }^{3}$ Furthermore, CS increases the virulence of pathogens, increasing the risk of pulmonary infections. ${ }^{4}$

\section{ALVEOLAR MACROPHAGES}

Macrophages are present in almost all tissues of the body. ${ }^{5}$ They derive their name from makros and phagein, Greek for 'big eater' after their primary bacterial killing mechanism, phagocytosis. In the lung, they are the most abundant immune cell present under homeostatic conditions, representing over $90 \%$ of the alveolar immune cells. As sentinel cells, AMs play an important gatekeeping role in innate immunity within the respiratory tract. AMs classically exert regulatory effects via non-specific immunedefence mechanisms such as phagocytosis, the production of inflammatory mediators such as reactive oxygen species (ROS) and the expression of inflammatory cytokines such as interleukin (IL)-1, IL-2, IL-4, IL-6, IL-8, tumour necrosis factor- $\alpha$ (TNF $\alpha$ ) and interferon gamma (IFN $\gamma$ ). AMs also resolve inflammation via the release of anti-inflammatory mediators and clearance of apoptotic bodies (efferocytosis). Therefore, AMs both initiate and resolve the immune the response, as well as having a role in surfactant/lipid processing and iron homeostasis.

\section{Ontogeny/lifespan}

Once thought to originate from circulating monocytes from the bone haematopoietic stem cells (HSCs), ${ }^{6}$ mechanistic murine work has indicated that AMs are initially derived from the yolk sac in foetal development and are independent of the HSC under homeostatic conditions. It is becoming clearer that resident lungresident AMs maintain their population during homeostasis by proliferation in situ rather than having a reliance on the macrophage precursors in the blood. ${ }^{78}$ Whereas during ongoing inflammation, monocytes are recruited to the lung and develop into AM-like cells. ${ }^{9}{ }^{10}$ Studies looking at chimerism in lung transplant recipients have shown evidence of donor persistence of $\mathrm{AMs},{ }^{11}$ that can persist up to 2 years. ${ }^{12}$ However, in the inflammatory state in patients after transplant and in healthy older volunteers, the majority of human AM originate from circulating monocytes. $^{13}$

\section{Lung monocyte/macrophage populations}

Distinct monocyte/macrophage populations in the lung can be defined as AMs, interstitial macrophages (IMs) and monocyte-derived cells according to their cell surface phenotype (see figure 2). Lung macrophages express the mannose receptor CD206, which has a role in recognition of microbial carbohydrates and mediating phagocytosis. This receptor is not detected in monocytes within the blood or intravascular compartment. ${ }^{14}$ AMs reside within the airway lumen and alveolar space, in contact with both the airway environment and epithelium. They are recognised by their distinctively high side scatter, high expression of CD206 and relatively low expression of monocyte marker CD14. IMs are located between alveolar epithelial cells, and unlike AMs, are negative for CD169

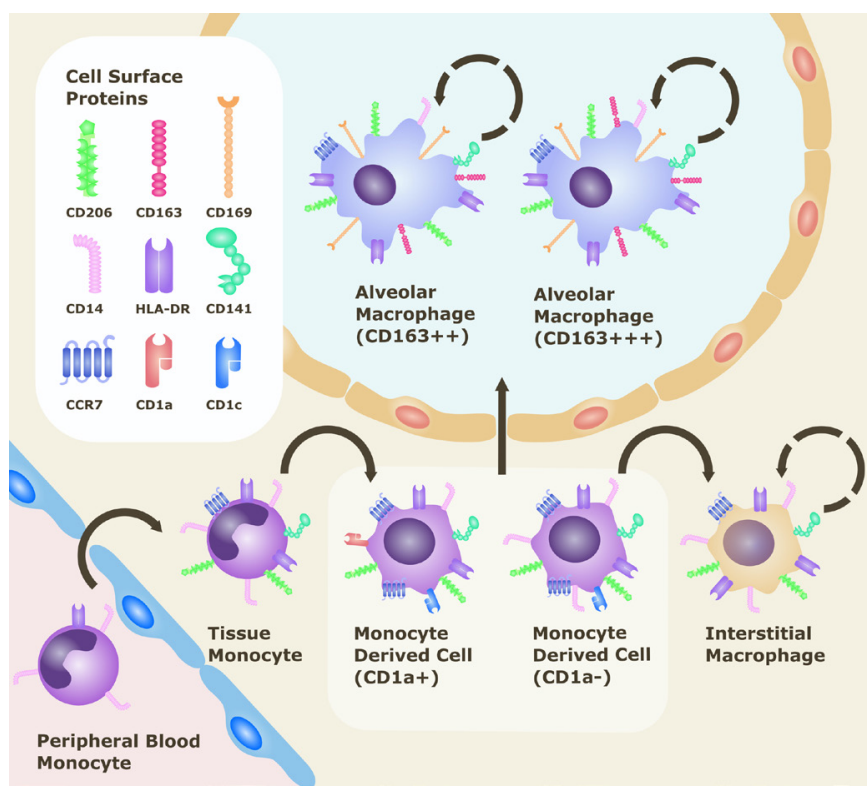

Figure 2 Cell surface markers of monocyte/macrophage populations within the lung.

(Siglec-1 or sialoadhesin), a cell adhesion molecule shown to discriminate phenotype between AMs (CD206+CD169+) and IMs (CD206+CD169-). ${ }^{15}$ AMs can be further subdivided by levels of expression of the high affinity-scavenger receptor CD163 (CD163 + + or CD163+++ subpopulations). ${ }^{16}$ Within the lung there is also a population of immature, infiltrating CD14+ pulmonary monocyte-derived cells, thought to be recently recruited into the extravascular space. These can be distinguished from the intravascular CD14+ monocytes by their expression of CD206 as well as other markers CD141, CD11c, human leukocyte antigen DR (HLA-DR) and CC-chemokine receptor type 7 (CCR7), with CD1a and CD1c allowing further categorisation of these cells. ${ }^{14}$

\section{Phenotype and normal function in airways}

Macrophages have been shown to exhibit plasticity and can change their phenotype depending on the local environment. Macrophages have traditionally been described to form two distinct polarised phenotypes in vitro following cytokine exposure of monocyte-derived macrophages (MDMs). 'M1 macrophages' are classically activated, typically by lipopolysaccharide (LPS), IFN $\gamma$ and/or TNF $\alpha$, and are involved direct destruction of intracellular pathogens, and produce pro-inflammatory cytokines, as well as a T helper 1 (Th1)-cell environment. 'M2 macrophages' are alternatively activated, typically by IL-4 and IL-10 and are a more heterogeneous group and involved in downregulating inflammation or pro-resolution and tissue repair, producing a Th2 environment. M1 and M2 have been largely unaltered since their initial classification ${ }^{17}$; M2 roles have been further categorised into $\mathrm{M} 2 \mathrm{a}$ (parasite destruction) $2 \mathrm{~b}$ (immune regulation) and $2 \mathrm{c}$ (tissue remodelling and extracellular matrix (ECM) deposition). ${ }^{18}$ With regards to cell surface markers, M1 are typically characterised by expression of HLA-DR, CD14 and CD38, while M2 are characterised by CD36, CD206 and CD163. Many studies have looked at M1/M2 with relevance to disease. However, more recently studies have moved away from this model; in vivo these phenotypes exist as part of a spectrum and many of the M1/M2 markers are co-expressed on the 
same macrophages, such as CD206 ubiquitously expressed by all pulmonary macrophages. ${ }^{14}$

\section{CS EXPOSURE AND AM RECRUITMENT Increased AM and neutrophil chemotaxis}

Smoking induces an increase in immune cells within the lung (4-5 fold), as assessed by bronchoalveolar lavage (BAL) ${ }^{19}$ with most of the increase attributed to the AM cellularity. ${ }^{20}$ The increased cellularity of both AM and neutrophils may be explained by chemotactic factors generated in the lung. CS exposure activates the pro-inflammatory transcription factor nuclear factor kappa $\mathrm{B}(\mathrm{NF}-\kappa \mathrm{B})$ and increases messenger RNA (mRNA) expression of IL-8 (one of the mediators controlled by NF- $\kappa B$ ) within the macrophages. ${ }^{21} 22$ This process is at least partially an autologous effect, with other cells such as bronchial epithelial cells shown to release increased IL-8 in response to CS that would contribute to stimulate macrophage and neutrophil influx. ${ }^{23}$ The increased BALF cellularity may take over 1 month to significantly reduce and up to 6 months to fully normalise. ${ }^{24}$

\section{Accumulation of autofluorescent bodies}

AMs from smokers contain autofluorescent bodies ${ }^{25}$ due to the uptake of CS particles (ie, 'tar'). Even short-term ex-vivo AM exposure to tar results in an increase in autofluorescence. ${ }^{26}$ These smoking-related inclusions can continue for up to 270 days after cessation ${ }^{27}$ and have been found on autopsy of patients who had stopped smoking 2 years prior. ${ }^{28}$ This has been shown to be the case in other studies that have investigated AMs from BAL between healthy smokers and non-smokers. ${ }^{25}$ Furthermore, the autofluorescence is not related to amount of exposure, such as pack year consumption. ${ }^{29}$ This suggests a maximum possible capacity of tar uptake, anything beyond this point will not be retained, destroying any dose response seen in earlier stage of exposure. There is also the factor of AM flux and turnover that may contribute to lack of dose effect at very high CS exposure levels.

\section{CS EXPOSURE AND AM PHENOTYPE $M 1 / M 2$ polarisation and disease states}

In studies looking at the AM M1/M2 polarisation paradigm, CS has been reported to reduce phenotypic markers of M1 phenotype $e^{3031}$ and/or increase markers of M2 phenotype p $^{3233}$ implicated in dysregulated inflammation. Using immunohistochemistry to quantify polarisation of M1 (iNOS) and M2 (CD206) phenotype in lung tissue, in normal lungs AMs did not show M1 or M2 polarisation and instead dual expressed both markers of polarity, with the majority negative for M1 and M2 markers. ${ }^{30}$
In smokers and in COPD disease severity, AMs increased dual expression of both M1 and M2 markers. ${ }^{30}$ In early lung cancer, tumour-associated macrophages (TAMs) also showed co-expression of M1 (chemokine (C-X-C motif) ligand 9 (CXCL9)) and M2 (matrix metalloproteinase (MMP-12)) phenotypic markers, ${ }^{34}$ with single cell RNA-sequencing of TAMs showing uniform M2-like signature with varying degrees of M1-like signature. Those with $>80 \%$ of TAMs co-expressing a strong (hot) M1-like signature had a stronger density of CD8+ tissueresident memory $\mathrm{T}$ cells in tumours and an improved survival.

In the relationship of CS exposure and AM polarity, studies looking at gene expression profile have compared AMs to MDMs polarised to M1 or M2 in vitro using cytokines; forming either unstimulated, M1-polarised (IFN $\gamma$ and LPS-treated) and M2apolarised (IL-4-treated) macrophages. ${ }^{35}$ Microarray mRNA data suggest that smoking promotes an 'inverse' M1 gene expression profile defined by decreased expression of M1-induced transcripts $^{36}$ and increased expression of M1-repressed transcripts with few changes in M2-regulated transcripts. ${ }^{37}$ Thus, AM M1/ M2 phenotype exists as a spectrum, can be modified through CS exposure and relates to lung disease states and outcomes.

\section{Altered cell surface marker expression and maturity}

Smoking alters the phenotype of AMs, with observed differences in cell surface marker expression compared with nonsmokers (table 1). Smoking increased expression of CD14 and reduced expression of CD71 in a monocyte/macrophage population from BAL. ${ }^{38}$ Absence of the transferrin receptor CD71 in AMs is characterised by reduced expression of mature markers, impaired phagocytosis and expression of profibrotic genes. ${ }^{39}$ In COPD, lung macrophages from smokers expressed lower levels of the high affinity-scavenger receptor CD163 and lower levels of the non-opsonic receptor CD36 compared with ex-smokers. ${ }^{40}$ CD163 and CD36 both have an important role in efferocytosis, which is the clearance of apoptotic cells. ${ }^{41}$ CD91 has a role in phagocytosis as part of the CD91-calrecticulin mannose receptor complex. It has been shown to be reduced in expression in AMs from healthy smokers and COPD smokers when compared with never smokers. ${ }^{38} \mathrm{CD} 31$ (platelet endothelial cell adhesion molecule) is a surface marker that has been reported to promote tethering of apoptotic cells and is reduced in AMs from smokers. ${ }^{38}$ Blocking of CD91 and CD31 has shown to reduce AM efferocytosis. ${ }^{38} \mathrm{CD} 44$ is involved in clearing of hyaluronan, lipid metabolism, surfactant processing and efferocytosis, all which have a role in regulating inflammation; CD44 is reduced in AM from smokers when compared with non-smokers. ${ }^{38}{ }^{42}$ CD11c is an integrin that mediates cell-cell and cell to matrix interactions

\begin{tabular}{|c|c|c|c|}
\hline $\begin{array}{l}\text { Cell surface } \\
\text { marker }\end{array}$ & Function & $\begin{array}{l}\text { Level of expression in } \\
\text { smokers }\end{array}$ & Reference \\
\hline CD11c & Integrin alpha X chain; adherence to stimulated endothelium and phagocytosis of complement-coated particles & $\uparrow$ & 314344 \\
\hline CD14 & Co-receptor working with toll-like receptors; facilitates response to lipopolysaccharide & $\uparrow$ & 38 \\
\hline CD16 & Type III Fc gamma binds immunoglobulin; participates in signal transduction and phagocytosis & $\downarrow$ & 43 \\
\hline CD31 & Platelet endothelial cell adhesion molecule; promotes tethering of apoptotic cells in efferocytosis & $\downarrow$ & 38 \\
\hline CD36 & Scavenger receptor; regulates efferocytosis of apoptotic neutrophils and role in fatty acid uptake and lipid metabolism & $\downarrow$ & 40 \\
\hline CD44 & Cell surface glycoprotein involved in cell-cell interactions, adhesion and migration; receptor of efferocytosis & $\downarrow$ & 3842 \\
\hline CD54 & Intercellular adhesion molecule-1; involved in cell-cell interactions and leucocyte migration & $\downarrow$ & 4345 \\
\hline CD71 & Transferrin receptor; role in iron metabolism and iron import into cells through endocytosis & $\downarrow$ & 3845 \\
\hline CD91 & Low density lipoprotein receptor-related protein; binds to collagen like region on lung collectins and role in phagocytosis & $\downarrow$ & 38 \\
\hline CD163 & Scavenger receptor for haemoglobin-haptoglobin complex; innate immune receptor for bacteria and can be influenced by corticosteroids & $\downarrow$ & 40 \\
\hline
\end{tabular}


and is expressed at higher levels in healthy smokers compared with non-smokers. ${ }^{31} 4344$ CD54, also known as intercellular adhesion molecule-1, has a major role in immune and inflammatory regulation and has been shown to be expressed in lower levels in AMs from smokers compared with non-smokers. ${ }^{43} 45$ CD169 is a cell marker used to characterise AMs/IMs, however, little is known about the affects of CS exposure on expression. CD169 has been shown to be involved in phagocytosis of nontypeable Haemophilus influenzae and levels reduced in COPD ex-smokers compared with non-COPD ex-smokers, however, current and recent ex-smokers (2 months) were not assessed. ${ }^{46}$

Therefore, smoking influences the phenotype of pulmonary macrophages, resulting in more undifferentiated immature monocyte-like macrophages with a reduction in the mature AM surface markers needed for phagocytosis, efferocytosis, cellcell and cell to matrix interactions. The increase in the immature macrophages seen in smokers may be due to the influx of monocyte-derived cells from the peripheral blood, with the additional increase due to AM proliferation within the lung. ${ }^{38}$

\section{CS EXPOSURE AND AM IMMUNE FUNCTION Transcriptional profile and inflammation}

A number of studies have looked at the transcriptional profiles of human AMs isolated from smokers compared with nonsmokers. ${ }^{36478}$ The differential in gene expression belongs to the functional categories of immune/inflammatory response, lysosomal function, antioxidant-related function, signal transduction, regulation of transcription, cell adhesion, ECM and proteinase/anti-proteinase production. ${ }^{48}$ One such difference was an increase in osteopontin expression in smokers (fourfold), which was confirmed at the protein level and correlated with airflow obstruction. Osteopontin has a role in macrophage recruitment and is typically increased in response to proinflammatory cytokines (TNF $\alpha$, IL-1 $\beta$, transforming growth factor (TGF)- $\beta$ ). ${ }^{47} \mathrm{CS}$ exposure has also been shown to increase $\mathrm{TNF} \alpha$, which is central to acute smoke-induced inflammation and resulting connective tissue breakdown ${ }^{49}$ a precursor of emphysema development.

Cytochrome P450 (CYP) enzymes play an important role in activation of the CS procarcinogens to reactive metabolites that cause DNA damage,$^{50}$ with CYP1B1 found to be the most highly induced gene in AMs from smokers. ${ }^{47}$ In addition, PAH-DNA adducts are higher in AMs from smokers, related to pack year consumption and were increased in smokers with higher levels of CYP3A. ${ }^{51}$ Thus, AMs play a role in the metabolism of carcinogens in CS exposure, which may contribute to lung cancer development.

\section{Impaired bactericidal and phagocytotic processes/functions}

Detection and phagocytosis of foreign particulates and microbial matter is key to AM function and, in many cases, is the first step in orchestrating an immune response to infection. More frequently, within the airway, non-opsonised phagocytosis occurs via scavenger receptors, leading to cytoskeletal rearrangements and particle engulfment. ${ }^{52}$ This process results in a phagosome, which fuses with the lysosome to form the phagolysosome, with subsequent acidification to destroy the foreign particle/organism.

Innate recognition of pathogen-associated molecular patterns (PAMPs) is mediated by evolutionarily conserved pattern recognition receptors (PRRs). Toll-like receptors (TLRs) comprise a family of PRRs that are capable of recognising distinct PAMPs. TLR2 surface marker expression is reduced in AMs from smokers and levels of mRNA and protein expression did not increase in response to LPS stimulation compared with that in non-smokers, ${ }^{31}$ suggesting that continuous exposure to LPS present in CS may down-modulate antimicrobial response. ${ }^{53}$ TLR4 surface markers also recognise LPS from gram-negative bacteria. TLR4 expression is reduced in MDMs following CS exposure, ${ }^{54}$ with associated increased intracellular ROS and reduced antioxidant glutathione, which is implicated in oxidative stress and lung inflammation and seen in the pathogenesis of emphysema.

AMs play a key role in bacterial infection. Depletion of AMs in murine models results in decreased containment and clearance of gram-negative bacteria Klebsiella pneumoniae as well as reduced overall survival. ${ }^{55} \mathrm{An}$ in vitro study found no difference in the ability for AMs from healthy smokers to phagocytose, but a deficiency in the antimicrobial (bactericidal) properties against gram-positive bacteria Listeria monocytogenes, implying a defect in immunoregulation of the $\mathrm{AM} .{ }^{56} \mathrm{CS}$ extract also impaired $\mathrm{AM}$ phagocytosis of non-typable $H$. influenzae, a frequent coloniser of the upper respiratory tract, which may be due to CS potentiating reduced phosphoinositide 3-kinase signalling, triggered by the gram-negative bacteria. ${ }^{57}$ Using bioparticles from the gramnegative bacteria Escherichia coli, AM phagocytosis has been shown to be impaired in patients with COPD who were current smokers when compared with patients with COPD who were ex-smokers. ${ }^{40} \mathrm{CS}$ exposure also causes bacteria to become more virulent, with reduced lysis and resistance to macrophage killing such as seen in gram-positive bacteria, Staphylococcus aureus. ${ }^{4}$ In this study, CS exposure altered surface charge and hydrophobicity of the bacterial cell wall, which confers resistance to killing by antimicrobial peptides, both effecting the pathogenicity as well as host susceptibility by impairment of AM function. CS also impairs AM phagocytic function against the opportunistic fungal pathogen Candida albicans in murine models after $15 \mathrm{~min}$ of CS exposure. ${ }^{58}$

AMs from smokers have been shown to have defective autophagy, ${ }^{59}$ a cellular function that removes unnecessary or dysfunctional cellular components and required to eliminate intracellular Mycobacterium tuberculosis. ${ }^{60}$ In addition, nicotine in CS extract has been shown to impair AM M. tuberculosis killing, ${ }^{61}$ which may play a role in the increased risk of M. tuberculosis infection in smokers.

In patients undergoing surgery, anaesthesia has also been shown to detrimentally affect AM phagocytic and antimicrobial function. ${ }^{62}$ During surgery and anaesthesia, smoking further reduces AM phagocytosis of non-opsonised and opsonised (pre-incubated with rabbit immunoglobulin $G$ anti-bovine serum albumin) ${ }^{62}$ albumin-coated fluorescent particles and killing of L. monocytogenes, which were halved compared with non-smokers. ${ }^{63}$ The expression of pro-inflammatory cytokines (TNF $\alpha$, IFN $\gamma$, IL-1 $\beta$ ) was increased only half as much in smokers. ${ }^{63}$ This supports the observed increased risk in postoperative pulmonary complications in patients who smoke before surgery. The effect of smoking cessation has been investigated $^{64}$; 4 hours after induction of anaesthesia, the decreases in antimicrobial function against L. monocytogenes were 1.5-3 times greater in AMs from current and recent ex-smokers (2 months) compared with never smokers. AMs from current and mid-term ex-smokers (2-6 months) mounted a blunted inflammatory response with only a $50 \%-20 \%$ increased expression of pro-inflammatory (TNF $\alpha$, IFN $\gamma$, IL-1 $\beta$ ) and anti-inflammatory (IL-10, IL-4) cytokines compared with never smokers.

\section{Proteinase/anti-proteinase imbalance and tissue destruction}

One of the causes of smoking-related lung damage is through the imbalance of proteolytic enzymes (proteinases) and their 
inhibitors secreted by AMs. MicroRNA (miRNA) profiling studies in human AMs found that the most strongly downregulated miRNA in smokers compared with non-smokers was miR-452, ${ }^{37}$ which has a role in inhibiting the expression of MMP-12, a proteinase which degrades elastin and causes emphysema. ${ }^{65}$ The same study found that global miRNA expression was $50 \%-60 \%$ less in AMs from smokers. ${ }^{37}$ This may be explained by the reduced expression of the cytosolic RNA endonuclease (DICER), ${ }^{66}$ that has a key role in cleaving precursor miRNAs into mature functional 20-22-nucleotide miRNAs. MMP-12 has been shown to be the third most highly induced gene in smokers (ninefold) compared with non-smokers ${ }^{47}$; MMP-12+ macrophages are also increased in BAL in smokers and those with patients with COPD. ${ }^{67}$ Furthermore MMP-12 can increase the expression of placenta growth factor (PGF), upregulating downstream signalling molecules of PGF and resulting in bronchial epithelial cell apoptosis and emphysema. ${ }^{68} \mathrm{AMs}$ also produce elastolytic cysteine proteinases that have the capacity to cause significant lung destruction, particularly in an acidic environment. ${ }^{69}$ Cathepsin $\mathrm{S}$ is another potent elastase, with expression and activity found to be increased in current smokers. ${ }^{70}$ Cystatin $\mathrm{C}(\mathrm{CysC})$ is a major constitutive secretory product of AMs and is the most important inhibitor to cysteine proteinases which are also produced by the cells. CysC forms complexes with cathepsins and regulates proteinase secretion or leakage from dying or diseased cells. CysC release has been shown to be downregulated in response to CS. ${ }^{71}$ Thus, CS tips the balance of proteinase/antiproteinase release from AMs, contributing to cell death alongside inadequate repair, with elastolysis and connective tissue destruction, all of which are involved in the pathology of emphysema.

\section{Dysregulated ROS production}

ROS is essential for innate immune response of AMs and is produced by the enzyme NADPH Oxidase 2 (NOX2). Activation of NOX2 requires translocation of cytoplasmic subunits $\left(\mathrm{p} 40^{p h o x}\right.$, $\mathrm{p} 47^{p h o x}$ and $\left.\mathrm{p} 67^{p h o x}\right)$ and the guanosine triphosphatebinding Ras-related C3 botulinum toxin substrate 2 (Rac2) to a membrane-bound heterodimer cytochrome. ${ }^{72}$ CS has shown to increase intracellular ROS and activate the cellular energy sensor AMP-activated protein kinase in a nicotine dependent manner, resulting in increased IL-8 cytokine production, ${ }^{73}$ which plays a role in lung inflammation.

Cadmium is a heavy metal of considerable toxicity found in CS, which has been shown to influence the phagocytic and microbiocidal capacity of murine AMs. ${ }^{74}$ Cadmium levels were significantly elevated (ninefold) in BAL from human smokers, which correlated with loss of membrane Rac2 and p $67^{\text {phox }}$ localisation and NOX2-derived ROS synthesis. ${ }^{75}$ In the same study, in CS exposed mice, cadmium inhibited Rac2 activation needed for the generation of ROS in lung macrophages, recovery of Rac2 function reduced Streptococcus pneumoniae bacterial burden and increased survival. This may explain, in part, a mechanism for lower respiratory tract infection susceptibility in smokers.

\section{Mitochondrial dysfunction and oxidative stress}

Mitochondria are essential organelles that act as the powerhouse of the cell by generating high amounts of energy though ATP by oxidative phosphorylation. There is increasing interest in the alteration of mitochondrial activity as a mechanism for AM dysregulation in CS-related lung disease. AMs from patients with COPD had increased basal mitochondrial ROS (mROS) expression, though were unable to increase mROS production in S. pneumoniae infection, thus reducing the late phase of intracellular bacterial killing. ${ }^{76}$ MDMs from COPD increased mROS in response to oxidative stress, but with a decreased mitochondrial membrane potential, indicating dysregulated mitochondrial function. ${ }^{77}$ The differences in these studies may reflect that AMs from the lungs are primed to have elevated mROS following bacterial exposure, whereas MDMs are yet to be primed to reveal the intrinsic defect described. Further understanding of the role of CS in mitochondrial function in AMs is needed as a potential therapeutic approach for improving phagocytosis and infective exacerbations in COPD.

\section{CS EXPOSURE AND AM HOMEOSTASIS}

\section{Surfactant/lipid processing and inflammation}

The AM has a role in regulating the surfactant layer coating the alveolar epithelium by clearing damaged and oxidised surfactant produced by the alveolar epithelial type II (AT2) cell ensuring low surface tension to prevent alveolar collapse. ${ }^{78} \mathrm{AMs}$ contribute to around $50 \%$ of surfactant turnover through degradation, with the remaining surfactant uptake and recycling by AT2 cells. ${ }^{79}$ Granulocyte macrophage colony-stimulating factor (GM-CSF) is required for the differentiation and functional activity of the AM in mice ${ }^{80}$ and has an important role in surfactant homeostasis. Absence of GM-CSF in humans is seen in pulmonary alveolar proteinosis, in which AMs are unable to catabolise surfactant lipids and proteins, resulting in an accumulation of pulmonary surfactant-associated proteins in the airways and associated inflammation.

CS exposure is associated with damaged pulmonary surfactant, inflammation and dysfunctional processing and lipid accumulation in AMs (a defining feature of foam cells); IL- $1 \alpha$-dependent inflammation following exposure is required to maintain surfactant homeostasis in the lungs through production of GM-CSF. ${ }^{81}$ In another murine study, CS exposure increased pulmonary GM-CSF and AM accumulation. Chronic GM-CSF exposure induced features of diffuse interstitial pneumonia, a smokingassociated parenchymal lung disease associated with AM accumulation, increased MMP-12 secretion, parenchymal lung disease and emphysema. ${ }^{82}$

Reverse lipid transport is crucial in pulmonary homeostasis and allows AMs to properly export intracellular lipids and cholesterols, most of which originate from the pulmonary surfactant. ATP-binding cassette transporter A1 (ABCA1) and G1 (ABCG1) have important roles in the exporting cell, as they bind to apolipoprotein A-1 (ApoA-1), the principal component of high-density lipoproteins (HDLs). Deficiencies of ABCA1 and ABCG1 increase lipid accumulation in AMs and chronic lung inflammation in mice. ${ }^{83}{ }^{84} \mathrm{CS}$ affects pulmonary expression of ABCA1 and ABCG1 in both humans and mice, with ApoA-1 deficient mice showing a $50 \%$ reduction in reverse lipid transport capacity, and increased lung neutrophilia and larger macrophage size in response to CS exposure. ${ }^{85}$ There is a potential role for augmenting reverse lipid transport. ApoA-1 overexpression in mice had a protective effect in attenuating inflammation and development emphysema following CS exposure. ${ }^{86}$

\section{Iron homeostasis and oxidative damage}

Iron homeostasis is important in the lung, as excess iron, particularly in the 'free' form produces toxic reactive hydroxyl radicals, and favours intracellular bacterial growth such as in $M$. tuberculosis infection. ${ }^{87}$ Intracellular iron is increased in AM from smokers ${ }^{88} 89$ and in patients with COPD and lung cancer. ${ }^{89}$ Release of extracellular iron and ferritin is higher in AMs from smokers compared with non-smokers and more-so in heavy 
smokers. ${ }^{90}$ CS and crocidolite (blue asbestos) exposure have been shown to have a synergistic role in promoting extracellular ferritin release by AMs. ${ }^{91}$ Thus, the increased extracellular iron from AMs is a potential source of oxidative damage and inflammation in the lung following CS exposure.

\section{Efferocytosis and resolution of inflammation}

Efferocytosis is the clearance of primarily apoptotic neutrophils in the setting of acute lung inflammation. During efferocytosis the cell membrane of the AM engulfs the apoptotic cell, forming a vesicle called the efferosome, preventing the apoptotic cell from breaching its membrane and leaking toxic elements such as enzymes, oxidants and proteinases into the surrounding tissue. Thus, efferocytosis requires the AM to adopt an antiinflammatory state in order to prevent inflammatory responses to self-proteins. ${ }^{92}$

Efferocytosis is reduced in AMs from smokers compared with never-smokers. ${ }^{93}$ AMs recognise apoptotic cells using cell surface receptors including CD44 (hyaluronan receptor), which is expressed at lower levels in smokers ${ }^{38}$ and is important for clearance of apoptotic neutrophils and the release of antiinflammatory and pro-repair mediators such as TGF- $\beta{ }^{94}$ CS has been shown to reduce efferocytosis in AMs through the interaction of AM with CS modified ECM proteins and aberrant surfactant processing. ${ }^{95}$ Defective efferocytosis of AMs may also be driven by the significantly increased levels of CS-induced oxidative stress. ${ }^{96}$ Another mechanism for reduced efferocytosis may be due to CS-induced defects in phagosome and the lysosome fusion, demonstrated in rat models. ${ }^{97}$

CS-reduced AM efferocytosis was restored through the delivery of GM-CSF to the alveolar space and was associated with reduced morbidity following influenza infection. ${ }^{98}$ In patients with COPD, AM efferocytosis was higher than in those who stopped smoking compared with those who continued to smoke, suggesting a CS-related effect on AM in COPD that may be partially resolved on smoking cessation. ${ }^{38}$ Following community acquired pneumonia, smokers had reduced AM efferocytosis, as were those who were not on a statin; suggesting that smoking and statins may have antagonistic effects on the Rac1 and RhoA pathway in influencing efferocytosis and inflammation resolution. ${ }^{99} \mathrm{CS}$ is known to affect pathways leading to the activation and membrane localisation of the enzyme Rac, which facilitates the cytoskeletal rearrangements needed for efferocytosis. ${ }^{100}$ Statins are a potential therapy to improve AM efferocytosis, as demonstrated in AMs from mice and patients with COPD. ${ }^{101}$ Macrolides including azithromycin are another potential therapy to rescue defective efferocytosis as shown in patients with COPD ${ }^{102}$ possibly due to an upregulation of CD206 but the mechanism remains to be fully elucidated. Glucocorticoids improve AM efferocytosis but decrease phagocytosis in murine models of $S$. pneumoniae. ${ }^{103}$ Thus, resolving efferocytosis may leave the AMs that have ingested apoptotic cells less able to recognise and kill bacteria. ${ }^{104}$ Therefore a balance must be struck between microbial clearance and pro-resolution.

\section{CONCLUSION}

CS has a plethora of effects on AMs with changes in phenotype, phagocytosis and bacterial killing, ROS production, proteinase/ anti-proteinase release, iron and lipid homeostasis and efferocytosis. Subsequent acute and chronic inflammation with inflammatory cell recruitment and resultant destruction/remodelling increases susceptibility to pulmonary infection and development of CS-induced lung diseases. Many of these smoking-induced changes on the AM persist following cessation in smoking, with the duration of cessation needed for partial or full resolution of phenotype and function largely unknown. E-cigarette vaping has shown similar effects to smoking on AM function, ${ }^{105}$ with shared mechanisms to CS exposure, though the perception is that they are a safer alternative. Further understanding of the mechanisms of CS on AMs and other lung monocyte/macrophages populations may allow novel ways of restoring cellular function in those patients to reduce risk of infection or further lung injury.

Contributors DRT and BN conceived the review. STL, AS and DP drafted the final manuscript. All authors have critically appraised and approved the final version for submission.

Funding AS and DRT are funded by the Medical Research Council (MR/L002736/1). Competing interests None declared.

Patient consent for publication Not required.

Provenance and peer review Not commissioned; externally peer reviewed.

Open access This is an open access article distributed in accordance with the Creative Commons Attribution Non Commercial (CC BY-NC 4.0) license, which permits others to distribute, remix, adapt, build upon this work non-commercially, and license their derivative works on different terms, provided the original work is properly cited, appropriate credit is given, any changes made indicated, and the use is non-commercial. See: http://creativecommons.org/licenses/by-nc/4.0/.

\section{ORCID iD}

Aaron Scott http://orcid.org/0000-0001-9325-5026

\section{REFERENCES}

1 Borgerding M, Klus H. Analysis of complex mixtures - cigarette smoke. Experimental and Toxicologic Pathology 2005;57:43-73.

2 Rennard SI. Cigarette smoke in research. Am J Respir Cell Mol Biol 2004;31:479-80.

3 Barnes PJ. Immunology of asthma and chronic obstructive pulmonary disease. Nat Rev Immunol 2008;8:183-92

4 McEachern EK, Hwang JH, Sladewski KM, et al. Analysis of the effects of cigarette smoke on staphylococcal virulence phenotypes. Infect Immun 2015;83:2443-52.

5 Murray PJ, Wynn TA. Protective and pathogenic functions of macrophage subsets. Nat Rev Immunol 2011;11:723-37.

6 van Furth R, Cohn ZA. The origin and kinetics of mononuclear phagocytes. Journal of Experimental Medicine 1968;128:415-35.

7 Jenkins SJ, Ruckerl D, Cook PC, et al. Local macrophage proliferation, rather than recruitment from the blood, is a signature of Th2 inflammation. Science 2011;332:1284-8.

8 Schulz C, Perdiguero EG, Chorro L, et al. A lineage of myeloid cells independent of Myb and hematopoietic stem cells. Science 2012;336:86-90.

9 Hashimoto D, Chow A, Noizat C, et al. Tissue-Resident macrophages self-maintain locally throughout adult life with minimal contribution from circulating monocytes. Immunity 2013;38:792-804.

10 Gibbings SL, Goyal R, Desch AN, et al. Transcriptome analysis highlights the conserved difference between embryonic and postnatal-derived alveolar macrophages. Blood 2015;126:1357-66.

11 Nayak DK, Zhou F, Xu M, et al. Long-Term persistence of donor alveolar macrophages in human lung transplant recipients that influences donor-specific immune responses. American Journal of Transplantation 2016;16:2300-11.

12 Eguíluz-Gracia I, Schultz HHL, Sikkeland LIB, et al. Long-Term persistence of human donor alveolar macrophages in lung transplant recipients. Thorax 2016;71:1006-11.

13 Byrne AJ, Powell JE, O'Sullivan BJ, et al. Dynamics of human monocytes and airway macrophages during healthy aging and after transplant. J Exp Med 2020;217. doi:10.1084/jem.20191236. [Epub ahead of print: 0203 2020].

14 Desch AN, Gibbings SL, Goyal R, et al. Flow cytometric analysis of mononuclear phagocytes in Nondiseased human lung and lung-draining lymph nodes. Am J Respir Crit Care Med 2016;193:614-26.

15 YR Y, Hotten DF, Malakhau Y. Flow cytometric analysis of myeloid cells in human blood, bronchoalveolar lavage, and lung tissues. Am J Respir Cell Mol Biol 2016;54:13-24

16 Bharat A, Bhorade SM, Morales-Nebreda L, et al. Flow cytometry reveals similarities between lung macrophages in humans and mice. Am J Respir Cell Mol Biol 2016:54:147-9.

17 Gordon S. Alternative activation of macrophages. Nat Rev Immunol 2003;3:23-35

18 Mantovani A, Sica A, Sozzani S, et al. The chemokine system in diverse forms of macrophage activation and polarization. Trends Immunol 2004;25:677-86.

19 Bronchoalveolar lavage constituents in healthy individuals, idiopathic pulmonary fibrosis, and selected comparison groups. The BAL cooperative group Steering Committee. Am Rev Respir Dis 1990;141:S169-202. 
20 Karimi R, Tornling G, Grunewald J, et al. Cell recovery in bronchoalveolar lavage fluid in smokers is dependent on cumulative smoking history. PLoS One 2012;7:e34232.

21 Nishikawa M, Kakemizu N, Ito T, et al. Superoxide Mediates Cigarette SmokeInduced Infiltration of Neutrophils into the Airways through Nuclear Factor- $\kappa \mathrm{B}$ Activation and IL-8 mRNA Expression in Guinea Pigs In Vivo. Am J Respir Cell Mol Biol 1999;20:189-98.

22 Koch A, Giembycz M, Stirling RG, et al. Effect of smoking on MAP kinase-induced modulation of IL-8 in human alveolar macrophages. Eur Respir J 2004:23:805-12.

23 Mio T, Romberger DJ, Thompson AB, et al. Cigarette smoke induces interleukin-8 release from human bronchial epithelial cells. Am J Respir Crit Care Med 1997;155:1770-6

24 Sköld CM, Hed J, Eklund A. Smoking cessation rapidly reduces cell recovery in bronchoalveolar lavage fluid, while alveolar macrophage fluorescence remains high. Chest 1992;101:989-95.

25 Pankow W, Neumann K, Rüschoff J, et al. Human alveolar macrophages: comparison of cell size, autofluorescence, and HLA-DR antigen expression in smokers and nonsmokers. Cancer Detect Prev 1995;19:268-73.

26 Pauly JL, Allison EM, Hurley EL, et al. Fluorescent human lung macrophages analyzed by spectral confocal laser scanning microscopy and multispectral cytometry. Microsc Res Tech 2005;67:79-89.

27 Agius RM, Rutman A, Knight RK. Human pulmonary alveolar macrophages with smokers' inclusions: their relation to the cessation of cigarette smoking. British journal of experimental pathology 1986;67:407-13.

28 Reiter C. Fluorescence test to identify deep smokers. Forensic Sci Int 1986;31:21-6.

29 Sköld CM, Eklund A, Halldén G, et al. Autofluorescence in human alveolar macrophages from smokers: relation to cell surface markers and phagocytosis. Exp Lung Res 1989;15:823-35

30 Bazzan $\mathrm{E}$, Turato $\mathrm{G}$, Tinè $\mathrm{M}$, et al. Dual polarization of human alveolar macrophages progressively increases with smoking and COPD severity. Respir Res 2017;18:40.

31 Droemann D, Goldmann T, Tiedje T, et al. Toll-Like receptor 2 expression is decreased on alveolar macrophages in cigarette smokers and COPD patients. Respir Res 2005;6:68.

32 Kim EY, Battaile JT, Patel AC, et al. Persistent activation of an innate immune response translates respiratory viral infection into chronic lung disease. Nat Med 2008; 14:633-40.

33 Melgert BN, ten Hacken NH, Rutgers B, et al. More alternative activation of macrophages in lungs of asthmatic patients. J Allergy Clin Immunol 2011;127:831-3

34 Garrido-Martin EM, Mellows TWP, Clarke J, et al. M1 hot tumor-associated macrophages boost tissue-resident memory $T$ cells infiltration and survival in human lung cancer. J Immunother Cancer 2020:8:e000778.

35 Martinez FO, Gordon S, Locati M, et al. Transcriptional profiling of the human monocyte-to-macrophage differentiation and polarization: new molecules and patterns of gene expression. J Immunol 2006;177:7303-11.

36 Shaykhiev R, Krause A, Salit J, et al. Smoking-dependent reprogramming of alveolar macrophage polarization: implication for pathogenesis of chronic obstructive pulmonary disease. J Immunol 2009;183:2867-83.

37 Graff JW, Powers LS, Dickson AM, et al. Cigarette smoking decreases global microRNA expression in human alveolar macrophages. PLoS One 2012;7:e44066

38 Hodge S, Hodge G, Ahern J. Smoking alters alveolar macrophage recognition and phagocytic ability: implications in chronic obstructive pulmonary disease. American journal of respiratory cell and molecular biology 2007;37:748-55.

39 Allden SJ, Ogger PP, Ghai P, et al. The transferrin receptor CD71 delineates functionally distinct airway macrophage subsets during idiopathic pulmonary fibrosis. Am J Respir Crit Care Med 2019;200:209-19.

40 Dewhurst JA, Lea S, Hardaker E, et al. Characterisation of lung macrophage subpopulations in COPD patients and controls. Sci Rep 2017:7:7143.

41 Savill J, Hogg N, Ren Y, et al. Thrombospondin cooperates with CD36 and the vitronectin receptor in macrophage recognition of neutrophils undergoing apoptosis. J. Clin. Invest. 1992;90:1513-22.

42 Pons AR, Noguera A, Blanquer D, et al. Phenotypic characterisation of alveolar macrophages and peripheral blood monocytes in COPD. Eur Respir J 2005;25:647-52

43 Lofdahl JM, Wahlstrom J, Skold CM. Different inflammatory cell pattern and macrophage phenotype in chronic obstructive pulmonary disease patients, smokers and non-smokers. Clin Exp Immunol 2006;145:428-37.

44 Schaberg $\mathrm{T}$, Lauer $\mathrm{C}$, Lode $\mathrm{H}$, et al. Increased number of alveolar macrophages expressing adhesion molecules of the leukocyte adhesion molecule family in smoking subjects: association with cell-binding ability and superoxide anion production. American Review of Respiratory Disease 1992;146:1287-93.

45 Sköld CM, Lundahl J, Halldén G, et al. Chronic smoke exposure alters the phenotype pattern and the metabolic response in human alveolar macrophages. Clin Exp Immunol 1996;106:108-13.

46 Tanno A, Fujino N, Yamada M, et al. Decreased expression of a phagocytic receptor Siglec-1 on alveolar macrophages in chronic obstructive pulmonary disease. Respir Res 2020;21:30.

47 Woodruff $\mathrm{PG}$, Koth LL, Yang YH, et al. A distinctive alveolar macrophage activation state induced by cigarette smoking. Am J Respir Crit Care Med 2005;172:1383-92.
48 Heguy A, O'Connor TP, Luettich K, et al. Gene expression profiling of human alveolar macrophages of phenotypically normal smokers and nonsmokers reveals a previously unrecognized subset of genes modulated by cigarette smoking. J Mol Med 2006;84:318-28

49 Churg A, Dai J, Tai $\mathrm{H}$, et al. Tumor necrosis factor-alpha is central to acute cigarette smoke-induced inflammation and connective tissue breakdown. Am J Respir Crit Care Med 2002;166:849-54

50 Shimada T, Hayes CL, Yamazaki H. Activation of chemically diverse procarcinogens by human cytochrome P-450 1B1. Cancer Res 1996;56:2979-84.

51 Piipari R, Savela K, Nurminen T, et al. Expression of CYP1A1, CYP1B1 and CYP3A and polycyclic aromatic hydrocarbon-DNA adduct formation in bronchoalveolar macrophages of smokers and non-smokers. Int J Cancer 2000;86:610-6.

52 Aderem A, Underhill DM. Mechanisms of phagocytosis in macrophages. Annu Rev Immunol 1999;17:593-623.

53 Hasday JD, Bascom R, Costa JJ, et al. Bacterial endotoxin is an active component of cigarette smoke. Chest 1999;115:829-35.

54 Sarir $\mathrm{H}$, Mortaz E, Karimi K, et al. Cigarette smoke regulates the expression of TLR4 and IL-8 production by human macrophages. J Inflamm 2009;6:12

55 Broug-Holub E, Toews GB, van Iwaarden JF, et al. Alveolar macrophages are required for protective pulmonary defenses in murine Klebsiella pneumonia: elimination of alveolar macrophages increases neutrophil recruitment but decreases bacterial clearance and survival. Infect Immun 1997:65:1139-46.

56 King TE, Savici D, Campbell PA. Phagocytosis and killing of Listeria monocytogenes by alveolar macrophages: smokers versus nonsmokers. J Infect Dis 1988; 158:1309-16

57 Martí-Lliteras P, Regueiro Verónica, Morey P, et al. Nontypeable Haemophilus influenzae clearance by alveolar macrophages is impaired by exposure to cigarette smoke. Infect Immun 2009:77:4232-42.

58 Ortega E, Barriga C, Rodríguez AB. Decline in the phagocytic function of alveolar macrophages from mice exposed to cigarette smoke. Comp Immunol Microbiol Infect Dis 1994;17:77-84.

59 Monick MM, Powers LS, Walters K, et al. Identification of an Autophagy Defect in Smokers' Alveolar Macrophages. J.i. 2010;185:5425-35.

60 Gutierrez MG, Master SS, Singh SB, et al. Autophagy is a defense mechanism inhibiting BCG and Mycobacterium tuberculosis survival in infected macrophages. Cell 2004;119:753-66.

61 Bai X, Stitzel JA, Bai A, et al. Nicotine impairs macrophage control of Mycobacterium tuberculosis. Am J Respir Cell Mol Biol 2017;57:324-33.

62 Kotani N, Hashimoto $\mathrm{H}$, Sessler DI, et al. Intraoperative modulation of alveolar macrophage function during isoflurane and propofol anesthesia. Anesthesiology 1998;89:1125-32.

63 Kotani $N$, Hashimoto $H$, Sessler DI, et al. Smoking decreases alveolar macrophage function during anesthesia and surgery. Anesthesiology 2000;92:1268-77.

64 Kotani $\mathrm{N}$, Kushikata $\mathrm{T}$, Hashimoto $\mathrm{H}$, et al. Recovery of intraoperative microbicidal and inflammatory functions of alveolar immune cells after a tobacco smoke-free period. Anesthesiology 2001:94:999-1006.

65 Hautamaki RD, Kobayashi DK, Senior RM, et al. Requirement for macrophage elastase for cigarette smoke-induced emphysema in mice. Science 1997;277:2002-4.

66 Gross TJ, Powers LS, Boudreau RL, et al. A microRNA processing defect in smokers' macrophages is linked to sumoylation of the endonuclease Dicer. J Biol Chem 2014;289:12823-34.

67 Babusyte A, Stravinskaite K, Jeroch J, et al. Patterns of airway inflammation and MMP-12 expression in smokers and ex-smokers with COPD. Respir Res 2007:8:81.

68 Hou H-H, Wang H-C, Cheng S-L, et al. Mmp-12 activates protease-activated receptor-1, upregulates placenta growth factor, and leads to pulmonary emphysema. Am J Physiol Lung Cell Mol Physiol 2018;315:L432-42.

69 Shapiro SD. The macrophage in chronic obstructive pulmonary disease. Am J Respir Crit Care Med 1999;160:S29-32.

70 Andrault P-M, Schamberger AC, Chazeirat T, et al. Cigarette smoke induces overexpression of active human cathepsin $S$ in lungs from current smokers with or without COPD. Am J Physiol Lung Cell Mol Physiol 2019;317:L625-38.

71 Chapman HA, Reilly JJ, Yee R, et al. Identification of cystatin C, a cysteine proteinase inhibitor, as a major secretory product of human alveolar macrophages in vitro. Am Rev Respir Dis 1990;141:698-705.

72 Singel KL, Segal BH. Nox2-Dependent regulation of inflammation. Clin Sci 2016:130:479-90.

$73 \mathrm{Ko} \mathrm{H-K}$, Lee H-F, Lin A-H, et al. Regulation of cigarette smoke induction of IL-8 in macrophages by AMP-activated protein kinase signaling. J Cell Physiol 2015;230:1781-93.

74 Loose LD, Silkworth JB, Simpson DW. Influence of cadmium on the phagocytic and microbicidal activity of murine peritoneal macrophages, pulmonary alveolar macrophages, and polymorphonuclear neutrophils. Infect Immun 1978:22:378-81.

75 Larson-Casey JL, Gu L, Jackson PL, et al. Macrophage Rac2 is required to reduce the severity of cigarette smoke-induced pneumonia. Am J Respir Crit Care Med 2018;198:1288-301. 
76 Bewley MA, Preston JA, Mohasin M, et al. Impaired mitochondrial microbicidal responses in chronic obstructive pulmonary disease macrophages. Am J Respir Crit Care Med 2017:196:845-55.

77 Belchamber KBR, Singh R, Batista CM, et al. Defective bacterial phagocytosis is associated with dysfunctional mitochondria in COPD macrophages. European Respiratory Journal 2019;54:1802244.

78 Hussell T, Bell TJ. Alveolar macrophages: plasticity in a tissue-specific context. Nat Rev Immunol 2014;14:81-93.

79 Gurel O, Ikegami M, Chroneos ZC, et al. Macrophage and type II cell catabolism of SP-A and saturated phosphatidylcholine in mouse lungs. Am J Physiol Lung Cell Mol Physiol 2001;280:L1266-72.

80 Guilliams M, De Kleer I, Henri S, et al. Alveolar macrophages develop from fetal monocytes that differentiate into long-lived cells in the first week of life via GM-CSF. J Exp Med 2013;210:1977-92.

81 Morissette MC, Shen P, Thayaparan D, et al. Disruption of pulmonary lipid homeostasis drives cigarette smoke-induced lung inflammation in mice. European Respiratory Journal 2015;46:1451-60.

82 Suzuki T, McCarthy C, Carey B. Increased pulmonary GM-CSF causes alveolar macrophage accumulation: mechanistic implications for desquamative interstitial pneumonitis. Am J Respir Cell Mol Biol 2019.

83 Bates SR, Tao J-Q, Collins HL, et al. Pulmonary abnormalities due to ABCA1 deficiency in mice. Am J Physiol Lung Cell Mol Physiol 2005;289:L980-9.

84 Baldán Ángel, Gomes AV, Ping P, et al. Loss of ABCG1 results in chronic pulmonary inflammation. J Immunol 2008;180:3560-8.

85 Jubinville Éric, Talbot M, Bérubé J-C, et al. Interplay between cigarette smoking and pulmonary reverse lipid transport. European Respiratory Journal 2017;50:1700681.

86 Kim C, Lee J-min, Park S-W, et al. Attenuation of cigarette Smoke-Induced emphysema in mice by apolipoprotein A-1 overexpression. Am J Respir Cell Mol Biol 2016:54:91-102.

87 Olakanmi O, Schlesinger LS, Britigan BE. Hereditary hemochromatosis results in decreased iron acquisition and growth by Mycobacterium tuberculosis within human macrophages. J Leukoc Biol 2007;81:195-204.

88 Thompson $A B$, Bohling $T$, Heires $A$. Lower respiratory tract iron burden is increased in association with cigarette smoking. J Lab Clin Med 1991;117:493-9.

89 Corhay JL, Weber G, Bury T, et al. Iron content in human alveolar macrophages. Eur Respir J 1992;5:804-9.

90 Wesselius LJ, Nelson ME, Skikne BS. Increased release of ferritin and iron by iron-loaded alveolar macrophages in cigarette smokers. Am J Respir Crit Care Med 1994;150:690-5.
91 Plautz MW, Bailey K, Wesselius LJ. Influence of cigarette smoking on crocidoliteinduced ferritin release by human alveolar macrophages. J Lab Clin Med 2000;136:449-56.

92 Fadok VA, Bratton DL, Konowal A, et al. Macrophages that have ingested apoptotic cells in vitro inhibit proinflammatory cytokine production through autocrine/paracrine mechanisms involving TGF-beta, PGE2, and PAF. J Clin Invest 1998;101:890-8.

93 Hodge S, Hodge G, Scicchitano R, et al. Alveolar macrophages from subjects with chronic obstructive pulmonary disease are deficient in their ability to phagocytose apoptotic airway epithelial cells. Immunol Cell Biol 2003;81:289-96.

94 Teder P, Vandivier RW, Jiang D. Resolution of lung inflammation by CD44. Science 2002;296:155-8.

95 Kirkham PA, Spooner G, Rahman I, et al. Macrophage phagocytosis of apoptotic neutrophils is compromised by matrix proteins modified by cigarette smoke and lipid peroxidation products. Biochem Biophys Res Commun 2004;318:32-7.

96 Kirkham P. Oxidative stress and macrophage function: a failure to resolve the inflammatory response. Biochem Soc Trans 2007:35:284-7.

97 Harris JO, Gonzalez-Rothi RJ. Abnormal phagolysosome fusion in pulmonary alveolar macrophages of rats exposed chronically to cigarette smoke. Am Rev Respir Dis 1984;130:467-71.

98 Subramaniam R, Mukherjee S, Chen H, et al. Restoring cigarette smoke-induced impairment of efferocytosis in alveolar macrophages. Mucosal Immunol 2016;9:873-83.

99 Wootton DG, Diggle PJ, Court J, et al. Recovery from pneumonia requires efferocytosis which is impaired in smokers and those with low body mass index and enhanced by statins. Thorax 2016;71:1052-4.

100 Noda N, Matsumoto K, Fukuyama S, et al. Cigarette smoke impairs phagocytosis of apoptotic neutrophils by alveolar macrophages via inhibition of the histone deacetylase/Rac/CD9 pathways. Int Immunol 2013;25:643-50.

101 Morimoto K, Janssen WJ, Fessler MB, et al. Lovastatin enhances clearance of apoptotic cells (efferocytosis) with implications for chronic obstructive pulmonary disease. J Immunol 2006;176:7657-65.

102 Hodge $\mathrm{S}$, Hodge $\mathrm{G}$, Jersmann $\mathrm{H}$, et al. Azithromycin improves macrophage phagocytic function and expression of mannose receptor in chronic obstructive pulmonary disease. Am J Respir Crit Care Med 2008;178:139-48.

103 Stolberg VR, McCubbrey AL, Freeman CM, et al. Glucocorticoid-Augmented efferocytosis inhibits pulmonary pneumococcal clearance in mice by reducing alveolar macrophage bactericidal function. J Immunol 2015;195:174-84.

104 McCubbrey AL, Curtis JL. Efferocytosis and lung disease. Chest 2013:143:1750-7.

105 Scott A, Lugg ST, Aldridge K, et al. Pro-Inflammatory effects of e-cigarette vapour condensate on human alveolar macrophages. Thorax 2018;73:1161-9. 